This item was submitted to Loughborough's Research Repository by the author.

Items in Figshare are protected by copyright, with all rights reserved, unless otherwise indicated.

\title{
A virtual reality and retailing literature review: Current focus, underlying themes and future directions
}

PLEASE CITE THE PUBLISHED VERSION

https://doi.org/10.1007/978-3-030-06246-0

\section{PUBLISHER}

Springer

VERSION

AM (Accepted Manuscript)

\section{PUBLISHER STATEMENT}

This work is made available according to the conditions of the Creative Commons Attribution-NonCommercialNoDerivatives 4.0 International (CC BY-NC-ND 4.0) licence. Full details of this licence are available at: https://creativecommons.org/licenses/by-nc-nd/4.0/

\section{LICENCE}

CC BY-NC-ND 4.0

\section{REPOSITORY RECORD}

Xue, Liangchao, Christopher J. Parker, and Helen McCormick. 2018. "A Virtual Reality and Retailing Literature Review: Current Focus, Underlying Themes and Future Directions”. figshare. https://hdl.handle.net/2134/36050. 


\title{
A Virtual Reality and Retailing Literature Review: Current Focus, Underlying Themes and Future Directions
}

\author{
Liangchao Xue a \\ Christopher J. Parker ${ }^{b}$, and \\ Helen McCormick ${ }^{\text {a }}$ \\ ${ }^{a}$ Faculty of Science and Engineering \\ The University of Manchester, United Kingdom \\ xueliangchao@icloud.com \\ ${ }^{\mathrm{b}}$ Loughborough Design School \\ Loughborough University, United Kingdom \\ C.Parker@lboro.ac.uk
}

\begin{abstract}
This literature review reveals the current research focus, underlying themes and prominent research gaps in the Virtual Reality (VR) literature. 89 journal articles from the 22 years are thematically analysed in order to non-obvious reveal interconnections and themes, including research focus over time and underlying themes by research discipline. Over half of all papers focus on the need to understand the VR shopping consumer, yet no consensus exists as to what the optimal experience is or how to design effective $\mathrm{v}$-Commerce stores. The most prominent research gaps are related to the unique HCI aspects in v-Commerce that influence shopping behaviours. The impact of this review is establishing the current challenges and future directions for academia in order to make v-Commerce a viable reality. Specifically, future research should focus on develop human factor theory in VR shop design (i.e. social dimension, eye-tracking etc.).
\end{abstract}

Keywords: Virtual Reality, Retail, e-Commerce, Human Factors, Augmented Reality, vCommerce

\section{Introduction}

This paper reviews Electronic Commerce (e-Commerce) and consumer technology focused literature in order to detect key gaps and limitations in the literature must be contrasted to key developments and proposed applications. Through this, future research shall be directed towards making Virtual Reality (VR) and Augmented Reality (AR) viable platforms for e-Commerce beyond the two-dimensional limitations of screens.

Previously literature reviews on Virtual Reality have been conducted in fields such as Education (Freina and Ott, 2015), Tourism (Guttentag, 2010), Military (Rizzo et al., 2011), Healthcare (Nichols and Patel, 2002), Clinical trial (Cook and Triola, 2009), Therapy (Moreira et al., 2013), Urban planning (Simpson, 2001), Entertainment/Gaming (Connolly et al., 2012) and Engineering (Cecil and Kanchanapiboon, 2007). However, retail, e-Commerce and Virtual Commerce (vCommerce) are absent from contemporary VR/ AR literature reviews, presenting a void in academic knowledge which needs to be addressed.

The aim of this literature review is to direct research projects into as yet under explored to increase the efficiency and effectiveness of the retail research community. To achieve this aim, three research objectives were created:

1. We need to reveal the current focus of VR/ AR research to appraise the research areas which are well understood and thus less suitable for innovative potential exploration. 
2. We need to expose underlying themes in the VR/ AR research outside of explicit research focus to understand which disciplines are under researched relating to beneficial technological applications.

3. We need to uncover the most prominent research gaps related to VR/ AR to direct research projects that shall address critical issues essential to technological breakthroughs.

In addressing the research objectives, this literature review makes the following key contributions:

- Over half of all papers focus on the need to understand the consumer experience integrating with (Section 3.1), and shopping through v-Commerce, yet no consensus as to what the optimal experience is or how to design effective v-Commerce stores exists (Section 3.3).

- The majority of papers include underlying themes relating to UX design and purchase behaviour motivators, despite the apparent technological focus of the majority of the literature (Section 3.2).

- The most prominent research areas that need addressing are shown to be related to the unique HCI aspects in v-Commerce that effectively influence shopping behaviours in order to make VR/ AR platforms financially viable (Section 3.3).

\section{Methodology}

The principle sampling method was protocol driven, outlining the academic databases, search terms and filters the outset of the investigation. To reduce the influence of database bias, three databases were selected for their excellence in the academic research community; Web of Science, Google Scholar and Scopus. The search terms used in the resource collection process has been identified as technology and consumer aspects; presented in Table 1. These were identified through a close initial reading of the most prominent VR/ AR literature (Bonetti, Warnaby, \& Quinn, 2018; Dacko, 2016; Papagiannidis, Pantano, See-To, Dennis, \& Bourlakis, 2017).

Table 1. Literature Review Search Terms

\begin{tabular}{|c|c|}
\hline Technology aspects & Consumer aspects \\
\hline $\begin{array}{ll}\text { - } & \text { 3D store } \\
\text { - } & \text { Future of shopping } \\
\text { - } & \text { Interactivity } \\
\text { - } & \text { Technological innovation } \\
\text { - } & \text { Technology retail } \\
\text { - } & \text { V-Commerce } \\
\text { - } & \text { Virtual environment } \\
\text { - } & \text { Virtual reality } \\
\text { - } & \text { Virtual reality retailing } \\
\text { - } & \text { Virtual shopping } \\
\text { - } & \text { Virtual social } \\
& \text { Vividness }\end{array}$ & $\begin{array}{ll}\text { - } & \text { Consumer perception } \\
\text { - } & \text { Consumer reaction } \\
\text { - } & \text { Consumer satisfaction } \\
\text { - } & \text { Consumer/purchase behaviour } \\
\text { - } & \text { Shopping experience } \\
\end{array}$ \\
\hline
\end{tabular}

To reflect the current state of research into VR/ AR, the literature review focused primarily on papers from 2016 onwards. However, inclusion of earlier work (2001 onwards) was allowed for historic comparisons to be drawn. Therefore, $70 \%$ of the papers were 2013 onwards. 
To discover more advanced literature than our preconceived notions of protocol driven search strategy would allow for, forward snowball sampling was applied; in line with recognised Literature Review guidelines (Jalali and Wohlin, 2012; Kitchenham and Charters, 2007). In this application, key papers on AR and VR were identified from the reference lists of significant articles, revealing important and influential material for the literature review.

Literature collection took place between October '17 and February '18, resulting in 89 pivotal journal articles being collected. Starting with Web of Science, each of the search terms (see Table 1) were sought, filtering by the criteria specified above. Selecting high-quality journals which review the literature, beginning with the most recent publications and work back in time. Papers deemed relevant were downloaded in PDF form and stored within NVivo 11. During the analysis of the journals, key cited papers were identified, before being found, critiqued, and subsequently downloaded. Once the snowball sampling trail had stopped being fruitful, the next search term was investigated in the same way. Following this, the additional search engines were checked for the search terms to ensure all key papers were identified. To keep up to date, continue searching the literature during analysis process. Only academic sources (journal articles, conference papers, periodicals and academic books) were accepted in the resource collection phase. This was to ensure the focus of the paper remained academic and grounded in scientific processes.

Thematic analysis was applied to the uncovered VR literature with the aid of NVivo 11. While manual coding techniques have proven successful in traditional literature reviews, the computational power of thematic analysis software helped gain a deeper insight into the data than otherwise possible. Resources were thematically analysed for the papers focus, future recommendations made, gaps and limitations highlighted in the literature, key findings, models, participant and the technology discussed. All data from this literature review (codebooks, classification sheets and figures) that can be made public is available through: doi.org/10.17028/rd.lboro.6177005.

\section{Literature Review Results}

\subsection{Current Research Focus on VR/ AR}

To reveal the current focus of VR/ AR research, Figure 1 shows the key areas of research discussed in the reviewed papers. These topics presented in the hierarchy chart give a picture of the current knowledge of VR/AR technology, retailers, customers and different shopping environment in the VR shopping field.

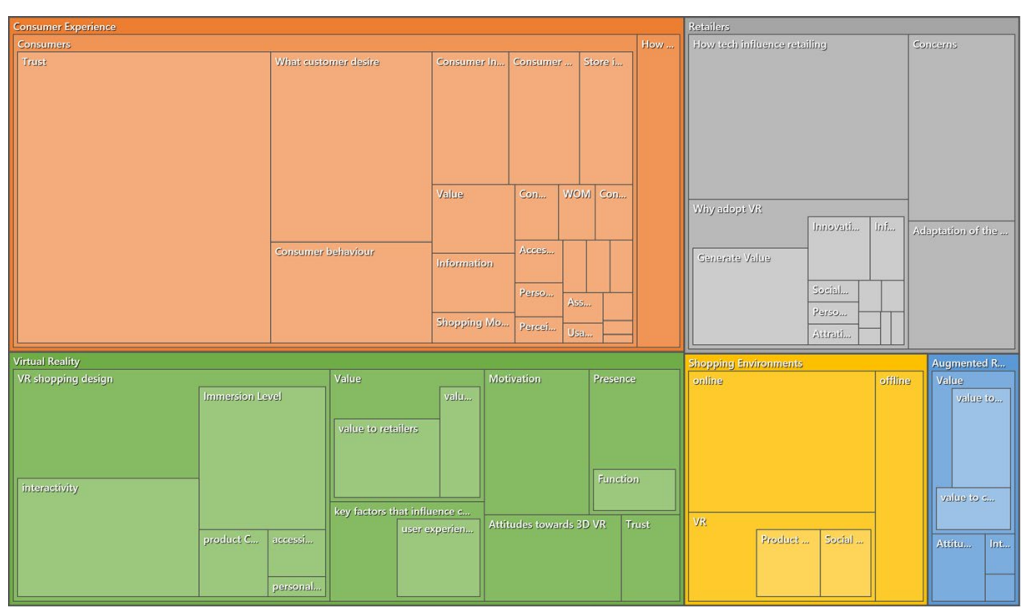

Figure 1. Hierarchy Chart showing Research Focus 
The key outcome of this analysis is how most research focuses on the Consumer Experience (orange) and the human factors of Virtual Reality (Green). This is despite the literature search focusing on technology literature; see Table 1. While inspecting research distribution over time (Figure 2) a convergence on the need to understand the human factors of the v-Commerce consumer occurs from 2016 onwards. These issues have been repeatedly highlighted for over 20 years, yet are still unanswered.

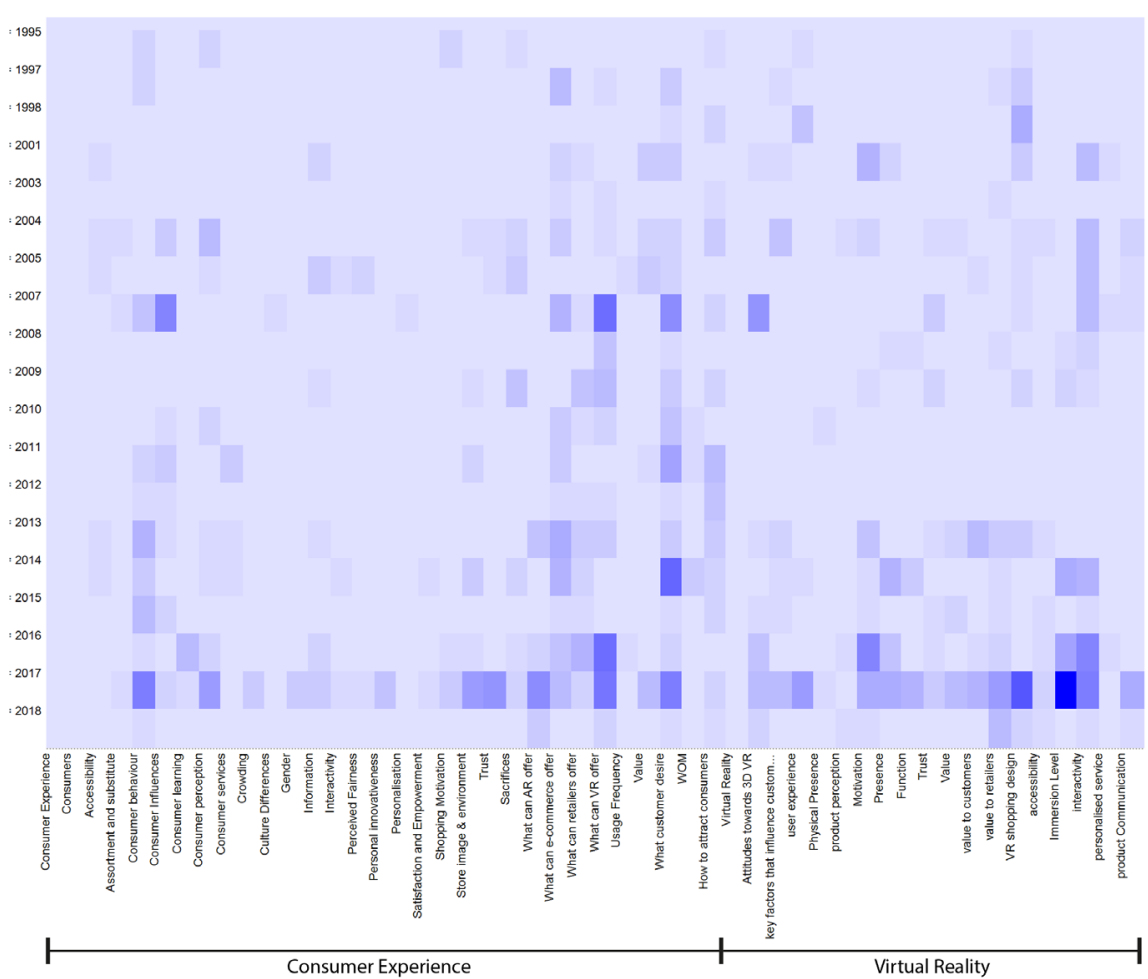

Figure 2. Heat Map of Prominent Research Focus Over Time

Critically, 15 papers state consumers are positive about AR/VR because they are new technologies that producing a significant novelty effect (Meißner, Pfeiffer, Pfeiffer, \& Oppewal, 2017; Yim, Chu, \& Sauer, 2017) and providing specific benefit such as efficiency and better shopping value (Dacko, 2016; Papadopoulou, 2007), which further lead to increase their shopping motivation (Altarteer et al., 2013). Recent market research revealed that $58 \%$ of customers consider shopping with digital technology will be more interesting (Perks, 2016), and $63 \%$ saying they expect such capabilities to change the way they shop (Parro and Santoro, 2015). While VR requires further improvements in terms of technical solution and operational business, as consumers are still perceive the virtual environment as being in the stage of development (Papagiannidis et al., 2017).

The second most important outcome is that $37 \%$ of all papers argue that retailers need to understand those factors that affect consumer perceptions. Specifically, they need to better understand the factors that influence v-Commerce consumers. These have been classified into comfort, content (environment, information, product display and product features), functionality (accessibility, interactivity, personalised service, vividness), media richness, perceived value (convenience, cost and trust), social networking and user experience (physical presence, product 
involvement and product perception). Therefore, these factors should be considered when developing VR shopping environment.

The third most important outcome relayed to value theory of VR. To understand consumer behaviours and examine the nature of the experience offered, it is necessary to investigate consumers and retailers and compare different shopping channel (offline; online and VR). Regarding value to retailers, eight papers state that VR shows great potential for retailers. As it is considered to be highly innovative and market leaders in the adoption of new technologies in the marketplace. As such, benefits to early adopters may be significant. Nine papers report that VR can also provide brand engagement and offer retailers a plethora of profound ways to educate the consumer about a brand, share their brand's story with customers, reinforce brand values and customer loyalty.

Regarding to value to consumers, 11 papers show that consumers' motivation can be considered as either hedonic value (for fun) or utilitarian value (for efficiency). Therefore, VR may provide value for consumer through these two aspects. Consumers can stay at home to compare or choose a certain product; reducing time and effort while shopping. Additionally, hedonic values refer to the emotional state generating from the experience and may include all elements (e.g. colour, music and other design elements) that contribute to a state of pleasure. Shoppers can receive value from these experiences, which their satisfaction and loyalty will be affected accordingly. There are benefits and costs associated with not only the products/ services being purchased online, but also the processes of obtaining them.

\subsection{Underlying Themes in the VR/ AR Literature}

To expose underlying themes in the VR/ AR research outside of explicit research focus, Figure 3 maps the literature disciplines against key themes common throughout the texts. Critically, these themes are discussed within the literature as separate to the explicit research focus presented within Section 3.2.

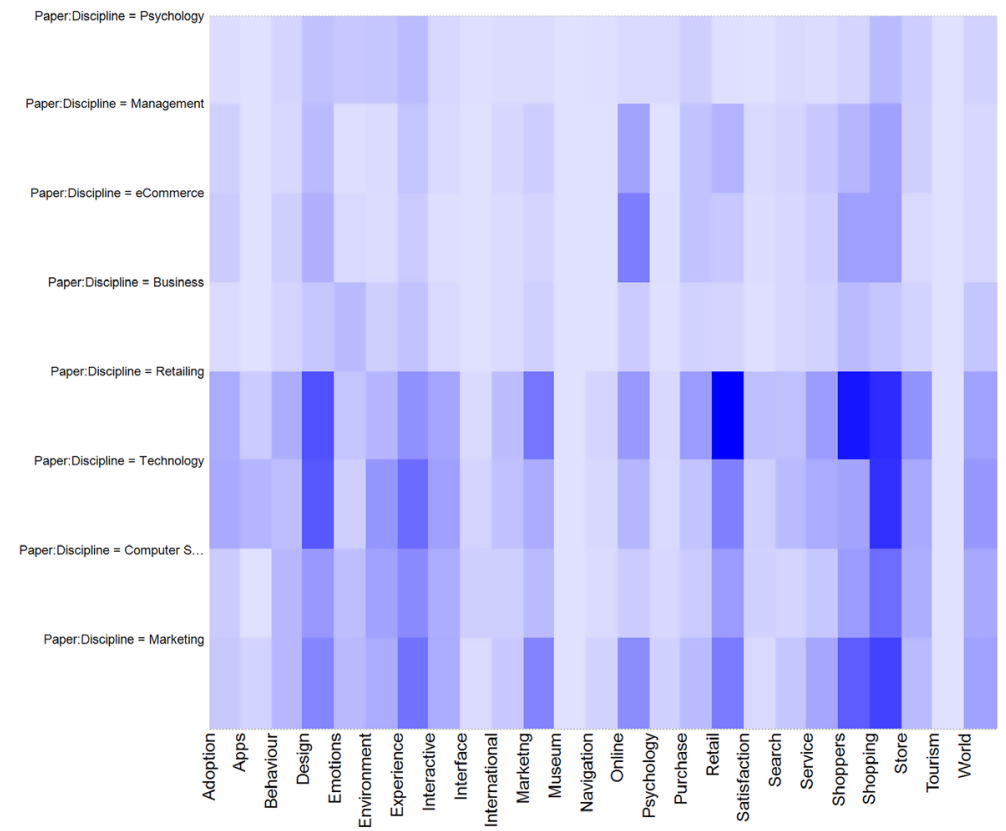

Figure 3. Heat Map of Underlying Themes vs. Research Discipline 
While key phrases such as shopping, online, shoppers and retail can be expected from the search terms of this review (see Table 1), many of the phrases coming from the word frequency search are both unexpected and intriguing. Terms such as 'service', 'museum' and 'tourism' demonstrate the considered application of VR/ AR outside the retail or physical items and into the commoditisation of experiences. One of the most interesting terms is 'design'. As fashion companies pursue of higher profit and market share though leverage VR shopping, future research is suggested to feed into the design and expansion of $\mathrm{v}$-Commerce platforms.

What is crucial though is that the majority of underlying themes centre on UX design or factors that influence buying behaviour. This contradicts the more widespread focus of research presented in Section 3.1. Consequently, while the literature may appear to address a wide range of topics, a convergence on the monetary application of VR/ AR in an e-Commerce context is of vastly higher prominence than development for experiential or technical benefits.

It is intriguing how website design research indicates that comfortable page layout, efficient search engines, updated information, clear navigational structures, simple checkout procedures and user-friendly interfaces were important to consumers' use of online shopping. These design features could also be applied in VR shop design. Similarly, the layout of store in the 3D environment is regulated by a different concepts because it operates under new store design conditions and customer navigation functions (Vrechopoulos et al., 2009). Despite this research requirement being made a decade ago, the unique HCI theory required to address it remains elusive within the VR/ AR literature. Thus it will increase commercial benefits through appropriate design of commercial premises (e.g., shopping malls (Huang et al., 2016).

Apart from design, another critical term is experience. Studies show that user experience refers to consumer participation and the environment relationship that results from the consumer interactions within a product, environment and brand. These have a holistic nature concerning cognitive, emotional, affective, social and physical responses to the shopping environment. On the other hand, Kolko (2009) suggests researchers focus on designing experiences rather than designing artefacts. It is expected that experience design become today's commercial art, for example, as Pine \& Gilmore (1998) suggested that create a theme that combines different product demonstrations together into one staged experience.

On the other hand, through exploring shopping environment of online and in-store, it is discovered that v-Commerce may have to make up for some of e-Commerce's inadequacies. This is because e-Commerce cannot include physical and tactile factors, which lack of product perception, and consumers may unable to compare products from the quality, size and style.

Therefore, in order to design effective v-Commerce shopping environments, designers should stand on the consumer's perception to understand the characteristics of consumers' acceptance of technology, keep abreast of technological innovation and market trends, etc. This is to help set up marketing and retail strategies to enrich and improve the consumer shopping experience effectively.

\subsection{Research Gaps with VR/ AR}

To uncover the most prominent research gaps related to VR/ AR, Figure 4 shows that the gaps in the current knowledge of virtual reality and retail sector. These gaps presented in the heat map need to be addressed through future research. 


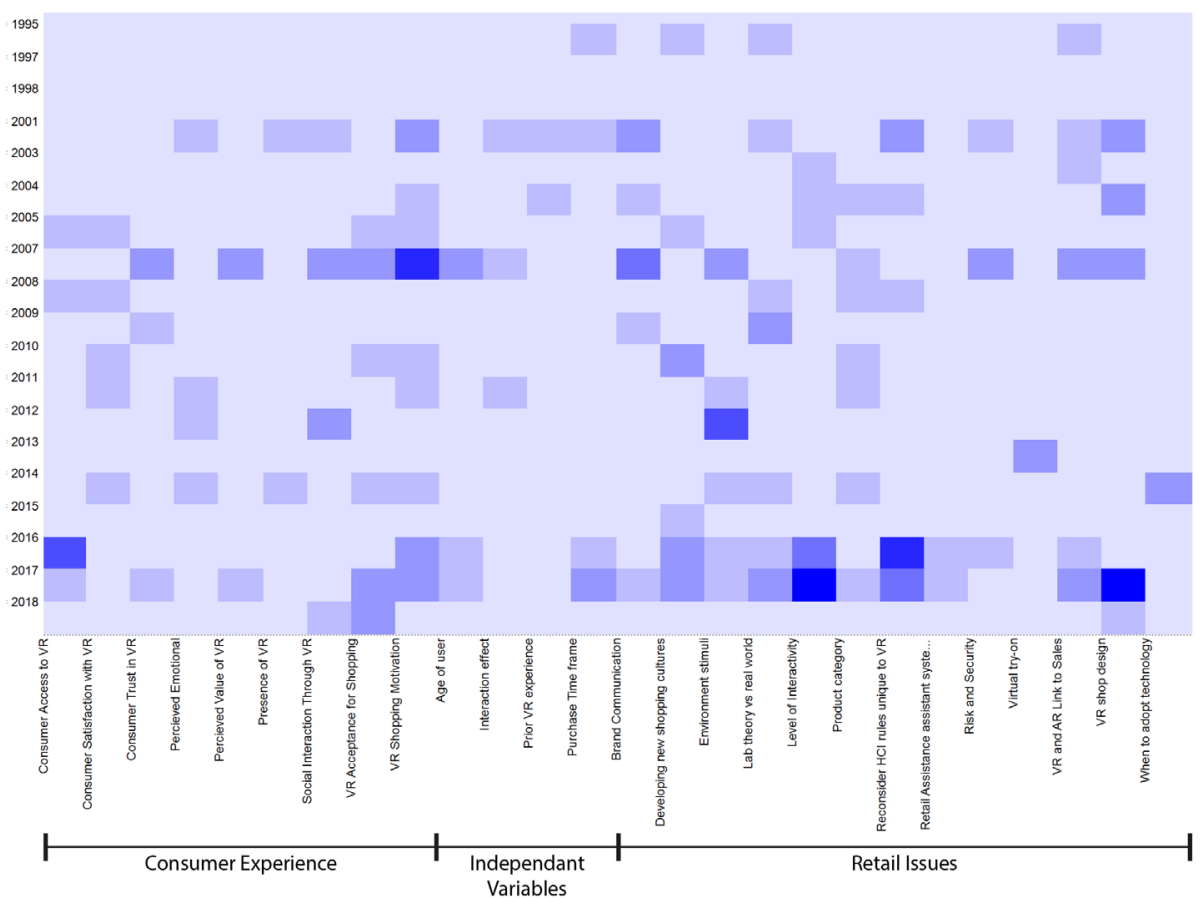

Figure 4. Heat Map Identified Showing Gaps in the Literature Against Time

The most resounding calls for research in recent years are Consumer access to VR (7), Level of Interactivity in retail environments (9), reconsideration of traditional HCI theory considering new interaction opportunities in VR/ AR (8) and how to design effective v-Commerce environments (8). While the prominence of these research themes has increased in recent years, they have, without exception, been called for by academics for over 13 years.

At a more holistic level, the most prominent questions in recent years relates to designing for $\mathrm{v}$ Commerce. While consumer experience has enjoyed equally important prominence between $2000-2015$, the reduction in authors calling for research into these areas suggests that the key questions in these areas have already been answered through existing research.

One important deficiency in the literature is the lack of influence variables concern towards vCommerce shopping. There are 32 papers called on researchers to examine these moderating variables, including age of user, the interaction effect, prior VR experience, purchase time frame and brand communication. Hence, future research will strongly focus on verify whether a number of independent variables that have been shown to affect consumer perception will have significant impact on virtual retailing.

Furthermore, $50 \%$ of all papers state that there are still major gaps in the knowledge related to VR shop design. First, only few studies incorporated social stimuli of the online environments as main constructs in the S-O-R framework. Therefore, the papers proposed further research should develop S-O-R in human-computer interaction environment and social dimension. Second, eyetracking, as an important technology for VR shopping, the challenges and efforts put into mobile eye-tracking studies are seldom made explicit in academic literature. Therefore, we suggest researchers incorporate eye-tracking methodologies into further VR studies. Third, there is no literature about user interface and design for disadvantages shoppers, which would be a very interesting area to engage with. 
Additionally, there are many gaps lie in consumer behaviour and VR/AR-related studies and how they link to sales. It is suggested that more in-depth investigation of human interaction to expand existing knowledge about consumer response to interactive technologies, as well as understand consumer behaviours and motivations within different sales channel. Moreover, Bonetti et al. (2018), Meißner et al. (2017) and Moorhouse et al. (2018) asked researchers to explore these technologies' acceptance.

To generate a bigger impact, $8 \%$ of papers also show that the experimental results generated in laboratories might differ from the real-world environment. Therefore, further research should request permission from real VR retailers to manipulate some of their stores' variables in order to run a field instead of a laboratory experiment, it would be very difficult but it is important for theory development (i.e. high external validity). To explore this further, future research should examine the impact of exposure to a Virtual Reality experience via pre- and post-usage measurements of the dependent variables. This also requires a longitudinal study in the future that will review this work and examine whether new outcomes are discovered and whether the immersive environment has become more 'accepted' and, thereby, participants perceive more experienced with VR.

\section{Discussion}

\subsection{Current Research Focus}

The current research extensively investigated the potential of AR/VR as a tool for e-Commerce, whether consumers will have a positive attitude toward these interactive technologies. Since VR/ AR currently has more enthusiasts than experts, which suggest that although the technologies are available, most consumers have yet to fully in engage with it. Accordingly, studies explore the value theory of AR/VR. Such technologies open up ample opportunities for retailers to connect with customers from their comfort home. Meanwhile, consumers benefit from both utilitarian and hedonic value. For example, reduce perceived crowding, increase user satisfaction, and then bring a competitive advantage for retailers. Through virtual try-on, reducing risk in customers' buying process, retailers then benefit from less return rate. However, these papers point out there are many factors will influence consumers' perceptions in v-Commerce shopping, including comfort, content, functionality, media richness, perceived value, social networking and user experience.

These findings enable us to appraise the research areas which are well understood and thus less suitable for innovative potential exploration in how VR is going to take over shopping malls and will help in making better decisions. However, in consideration of fictitious possibilities offered by virtual worlds, this positive perception then may not available when consumers are looking to buy products that are actually in use (Papagiannidis et al., 2017). Furthermore, the majority of consumers were also concerned about the devices' pricing along with peripherals, adapting the new technology, which concludes to be worried about the user friendliness of the complete system (Sharma and Bach, 2016). In addition, Papadopoulou (2007) argue that the procedure of shopping in the VR store is more time consuming than the conventional web, because they involved typing instead of clicking. Consequently, they are still perceive the virtual environment as being in the stage of development. The current knowledge still lacks understanding the unique human factors or $\mathrm{v}$-Commerce scenarios well enough to design effective and efficient retail platforms which justify the high access price (retailer platform development and consumer investment in technology).

The industry implications for these outcomes is that within the recent positive consumer response of virtual reality, v-Commerce is predicted to become next generation market platform. Therefore, it strongly encourages retailers to adopt such innovative technology either in-store or online to gain competitive advantages. Before adopting VR, company need to critical assess consumers' perception of the technology and ensure that dimensions that their customers view as being important are designed to be attractive to them. 


\subsection{Underlying Themes}

This review proves that in the current VR/ AR literature, the most prominent underlying themes are design and experience. The findings expose website design and virtual store design are important to home shopping. While the traditional retail store layout theory produces predictions that are not consistent with the virtual scene, as consumers are able to reach any virtual shop directly. Thus, more consumer-friendly user experience should be further developed to influence consumer buying behaviour online.

These findings enable us to understand which disciplines are under researched relating to beneficial technological applications in how current literature on VR has emphasised the retail and technological aspects of VR, but it has neglected the end user's needs and problem. Yet, VR is increasingly used in retail sector, even though research has not been able to catch up with the trend from a design perspective. Pantano (2015) suggests these technologies will help create new marketing experiences. In particular, $\mathrm{v}$-Commerce may combine the benefits of the electronic trading environment with the information richness of face-to-face trading through features that compensate for the loss of physical presence associated with e-Commerce (Chesney et al., 2017), such as absent of merchandising presentation, especially for clothing category (Kaplan and Haenlein, 2009). Thus, the questions that might bring to future are how to effective and efficient combine the value of online and offline shopping environments to v-Commerce, and what are the added-values we can create in v-Commerce to improve shopping experience.

The industry implications for these outcomes is that v-Commerce shopping should support the notion of providing a solution 'design for your needs'. It is important for retailers to mix the value from different sales channels and bring it to build user-friendly VR shopping.

\subsection{Research Gaps}

This review demonstrates that the most called for (yet unaddressed) research areas are the lack of influence variables concern towards v-Commerce shopping, the lack of knowledge related to VR shop design (social dimension, eye-tracking, disadvantages shoppers' considerations), the lack of understanding of how AR/VR link to sales, lack of understanding of VR acceptance for shopping and the experimental results generated in laboratories might be different from the realworld environment.

Figure 4 reflects that many studies calling for research VR shop design, while design aspect has been the focus a lot of papers for retailing and technology discipline. This means VR as a fresh technology, even though it has been introduced for a long time, researchers have only been paying attention to it since 2013. VR shopping design is an emerging research topic from 2017, thus a more sustained attention and a well-developed system are needed. Designers need to consider various influence factors that might affect shoppers' perception when developing virtual environment for retailing. These factors are not unique, but joins the growing body of research calling for better emotional and cognitive understanding in the consumer in order to develop more effective, and emotionally seductive e-Commerce platforms (e.g. Parker and Doyle, 2018; Parker and Wang, 2016).

The industry implications for these outcomes is that VR is emerging in design aspects to meet the consumer need, including user interface design, user experience design, visual merchandising etc. Successful completion of this research will enable a new means to understanding UI design for VR shopping and provide practical implications for multidisciplinary fields.

\section{Conclusion}

This paper set out to direct research projects into as yet under explored to increase the efficiency and effectiveness of the retail research community. Through thematic analysis of 89 pivotal journal articles, the main contribution of this paper is it signposts a clearer framework for locating future research inquiry and it highlights a research agenda that may provide the catalyst for this process. 
The implication of this review is that retailers should be realised that the today's shoppers may have high expectations from these immersive environments and, thus, they will require to adjust and take this into account when developing relevant strategies (Papagiannidis et al., 2017). It should be highlight that it is important to focus on store design features and user experience design to enhance the social dimensions of being a customer in a VR shop as well as the 'utilitarian' and the 'hedonic' dimensions. They should also integrate the benefits of online and offline shopping, which consumers most rely on (e.g. personal advice, after-sales service, etc.).

This literature review is limited in the scope of the VR search terms used (see Table 1) and the number of sources used in the search. While computational software NVivo has allowed for the analysis of most sources than before, a greater focus on papers before 2015 could provide a deeper insight into the research avenues that remain uncapitalized upon. Future research should focus on develop the fundamental human factors design theory for VR shopping environments, focusing on the lucrative fashion market, predicted to be worth $£ 64$ Billion by 2020 in the UK alone (Sender, 2016). This addresses the issue that until now, successful commercialisation remains elusive due to the lack of human factors theory to direct the interaction design process. Therefore, we need to understand:

1. The format of VR shopping experiences that consumers and retailers best respond to because this will allow designers to create virtual retail environments which efficiently encourage buying behaviours.

2. The ways VR shopping can offer retail experiences of higher value to target consumers than current retail environments because this will allow designers to focus on the retail areas that may profit most.

3. The barriers and enablers of VR adoption for fashion retailers because all commercially viable designs must overcome technological issues to diffuse in the marketplace.

\section{References}

Altarteer, S., Charissis, V., Harrison, D. and Chan, W. (2013), "Interactive virtual reality shopping and the impact in luxury brands", International Conference on Virtual, Augmented and Mixed Reality, Springer Berlin Heidelberg, pp. 221-230.

Altarteer, S., Vassilis, C., Harrison, D. and Chan, W. (2016), "Product customisation: virtual reality and new opportunities for luxury brands online trading", Proceedings of the 21st International Conference on Web3d Technology, ACM, pp. 173-174.

Bonetti, F., Warnaby, G. and Quinn, L. (2018), "Augmented Reality and Virtual Reality in Physical and Online Retailing: A Review, Synthesis and Research Agenda", in Jung, T. and tom Dieck, M.C. (Eds.), Augmented Reality and Virtual Reality: Empowering Human, Place and Business, Cham, Switzerland, pp. 119-132.

Cecil, J. and Kanchanapiboon, A. (2007), "Virtual engineering approaches in product and process design", The International Journal of Advanced Manufacturing Technology, Springer, Vol. 31 No. 9-10, pp. 846-856.

Chesney, T., Chuah, S.-H., Dobele, A.R. and Hoffmann, R. (2017), "Information richness and trust in v-commerce: implications for services marketing", Journal of Services Marketing, Vol. 31 No. 3, pp. 295-307.

Childers, T.L., Carr, C.L., Peck, J. and Carson, S. (2001), "Hedonic and utilitarian motivations for online retail shopping behavior", Journal of Retailing, Vol. 77 No. 4, pp. 511-535.

Connolly, T.M., Boyle, E.A., MacArthur, E., Hainey, T. and Boyle, J.M. (2012), "A systematic literature review of empirical evidence on computer games and serious games", Computers \& Education, Elsevier, Vol. 59 No. 2, pp. 661-686.

Cook, D.A. and Triola, M.M. (2009), "Virtual patients: a critical literature review and proposed next steps", Medical Education, Wiley Online Library, Vol. 43 No. 4, pp. 303-311.

Dacko, S.G. (2017), "Enabling smart retail settings via mobile augmented reality shopping apps", Technological Forecasting and Social Change, Elsevier Inc., Vol. 124, pp. 243-256.

Freina, L. and Ott, M. (2015), “A Literature Review On Immersive Virtual Reality In Education: 
State Of The Art And Perspectives", in Roceanu, I. (Ed.), The 11th International Scientific Conference ELearning and Software for Education, Carol I NDU Publishing House, Bucharest, pp. 133-141.

Guttentag, D.A. (2010), "Virtual reality: Applications and implications for tourism", Tourism Management, Vol. 31 No. 5, pp. 637-651.

Hendriksz, V. (2016), “Are consumers ready for Alibaba's VR Pay and Virtual Reality?", Fashion United, available at: https://fashionunited.com/news/business/are-consumersready-for-alibaba-s-vr-pay-and-virtual-reality/2016101413263 (accessed 25 May 2018).

Huang, H., Lin, N.-C., Barrett, L., Springer, D., Wang, H.-C., Pomplun, M. and Yu, L.-F. (2016), "Analyzing visual attention via virtual environments", SIGGRAPH ASIA 2016 Virtual Reality Meets Physical Reality: Modelling and Simulating Virtual Humans and Environments on - SA '16, ACM Press, New York, New York, USA, pp. 1-2.

Jalali, S. and Wohlin, C. (2012), "Systematic literature studies", Proceedings of the ACM-IEEE International Symposium on Empirical Software Engineering and Measurement - ESEM '12, ACM Press, New York, New York, USA, p. 29.

Kaplan, A.M. and Haenlein, M. (2009), "The fairyland of Second Life: Virtual social worlds and how to use them", Business Horizons, Vol. 52 No. 6, pp. 563-572.

Van Kerrebroeck, H., Brengman, M. and Willems, K. (2017), "When brands come to life: experimental research on the vividness effect of Virtual Reality in transformational marketing communications", Virtual Reality, Springer London, Vol. 21 No. 4, pp. 177191.

Kitchenham, B. and Charters, S. (2007), Guidelines for Performing Systematic Literature Reviews in Software Engineering, available at: https://userpages.unikoblenz.de/ laemmel/esecourse/slides/slr.pdf.

Kolko, J. (2011), Thoughts on Interaction Design, 2nd ed., Morgan Kaufmann, Burlington, MA, USA.

Lewrick, M., Omar, M., Williams Jr., R., Tjandra, N.C. and Lee, Z.-C. (2015), "Radical and Incremental Innovation Effectiveness in Relation to Market Orientation in the Retail Industry", in Pantano, E. (Ed.), Successful Technological Integration for Competitive Advantage in Retail Settings, IGI Global, Hershey, pp. 239-268.

Meißner, M., Pfeiffer, J., Pfeiffer, T. and Oppewal, H. (2018), "Combining virtual reality and mobile eye tracking to provide a naturalistic experimental environment for shopper research", Journal of Business Research, Vol. [In Press], available at:https://doi.org/10.1016/j.jbusres.2017.09.028.

Moorhouse, N., tom Dieck, M.C. and Jung, T. (2018), “Technological Innovations Transforming the Consumer Retail Experience: A Review of Literature", in Jung, T. and tom Dieck, M.C. (Eds.), Augmented Reality and Virtual Reality: Empowering Human, Place and Business, Springer International Publishing, Cham, pp. 133-143.

Moreira, M.C., de Amorim Lima, A.M., Ferraz, K.M. and Benedetti Rodrigues, M.A. (2013), "Use of virtual reality in gait recovery among post stroke patients-a systematic literature review", Disability and Rehabilitation: Assistive Technology, Taylor \& Francis, Vol. 8 No. 5, pp. 357-362.

Nichols, S. and Patel, H. (2002), "Health and safety implications of virtual reality: a review of empirical evidence", Applied Ergonomics, Elsevier, Vol. 33 No. 3, pp. 251-271.

Papadopoulou, P. (2007), "Applying virtual reality for trust-building e-commerce environments", Virtual Reality, Vol. 11 No. 2-3, pp. 107-127.

Papagiannidis, S., Pantano, E., See-To, E.W.K., Dennis, C. and Bourlakis, M. (2017), "To immerse or not? Experimenting with two virtual retail environments", Information Technology \& People, Vol. 30 No. 1, pp. 163-188.

Parker, C.J. and Doyle, S.A. (2018), "Designing Indulgent Interaction: Luxury Fashion, MCommerce, and Übermensch", in Ozuem, W. and Azemi, Y. (Eds.), Digital Marketing Strategies for Fashion and Luxury Brands, IGI Global, Hershey, USA, pp. 1-21.

Parker, C.J. and Wang, H. (2016), "Examining hedonic and utilitarian motivations for m- 
commerce fashion retail app engagement”, Journal of Fashion Marketing and Management, Vol. 20 No. 4, pp. 487-506.

Parro, D. and Santoro, M. (2015), Future of Retail Study: What Businesses Need to Know for 2015, Chicago, USA.

Perks, R. (2016), "Online Retailing - UK - July 2016", Mintel, London, UK, available at: http://academic.mintel.com/display/748703/ (accessed 29 May 2017).

Pine II, J.B., Gilmore, J.H., Pine, B.J. and Gilmore, J.H. (1998), "Welcome to the Experience Economy", Harvard Business Review, Harvard, USA, Vol. 76 No. 4, pp. 97-105.

Rizzo, A., Parsons, T.D., Lange, B., Kenny, P., Buckwalter, J.G., Rothbaum, B., Difede, J., et al. (2011), "Virtual reality goes to war: A brief review of the future of military behavioral healthcare", Journal of Clinical Psychology in Medical Settings, Springer, Vol. 18 No. 2, pp. 176-187.

Sender, T. (2016), "Clothing Retailing - UK - October 2016", Mintel, London, UK, available at: http://academic.mintel.com/display/748789/ (accessed 24 July 2017).

Sharma, S. and Bach, C. (2016), "An Exploratory Research on Virtual Reality and How it Affects Future of Shopping and Immerging Fields", European Journal of Engineering Research and Science, Vol. 1 No. 6, pp. 34-43.

Simpson, D.M. (2001), "Virtual reality and urban simulation in planning: A literature review and topical bibliography", Journal of Planning Literature, Sage Publications Sage CA: Thousand Oaks, CA, Vol. 15 No. 3, pp. 359-376.

Verhulst, A., Normand, J.-M., Lombart, C. and Moreau, G. (2017), "A study on the use of an immersive virtual reality store to investigate consumer perceptions and purchase behavior toward non-standard fruits and vegetables", 2017 IEEE Virtual Reality (VR), IEEE, pp. $55-63$.

Vrechopoulos, A., Apostolou, K. and Koutsiouris, V. (2009), "Virtual reality retailing on the web: Emerging consumer behavioural patterns", International Review of Retail, Distribution and Consumer Research, Vol. 19 No. 5, pp. 469-482.

Yim, M.Y.C., Chu, S.C. and Sauer, P.L. (2017), "Is Augmented Reality Technology an Effective Tool for E-commerce? An Interactivity and Vividness Perspective", Journal of Interactive Marketing, Direct Marketing Educational Foundation, Inc. dba Marketing EDGE, Vol. 39, pp. $89-103$.

Zhou, L. (2007), "a Critical Survey of Consumer Factors in Online Shopping”, Marketing Journal, Vol. 8 No. 1, pp. 41-62. 